\title{
Novel light-regulated genes in Trichoderma atroviride: a dissection by cDNA microarrays
}

\begin{abstract}
Correspondence
A. Herrera-Estrella

aherrera@ira.cinvestav.mx
\end{abstract}

Received 16 March 2006

Revised 19 July 2006

Accepted 26 July 2006

\author{
T. Rosales-Saavedra, ${ }^{1} \dagger$ E. U. Esquivel-Naranjo, ${ }^{1,2}$ S. Casas-Flores, ${ }^{1} \ddagger$ \\ P. Martínez-Hernández, ${ }^{1,2}$ E. Ibarra-Laclette, ${ }^{2}$ C. Cortes-Penagos ${ }^{2} \S$ \\ and A. Herrera-Estrella ${ }^{1,2}$
1,2Departamento de Ingeniería Genética ${ }^{1}$ and Laboratorio Nacional de Genómica para la

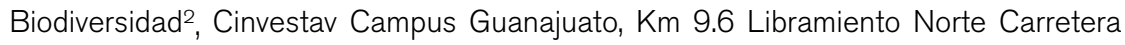 Irapuato-León, Apartado Postal 629, CP 36500, Irapuato, Guanajuato, Mexico

\section{INTRODUCTION}

Sunlight is a key environmental factor for the existence of life in our planet. In addition, it is a major environmental cue that determines the behaviour of living organisms. Among the diversity of responses triggered by light, important efforts have been directed to studying photomorphogenesis, phototropism, pigmentation and circadian rhythms (Linden et al., 1997; Briggs \& Huala, 1999). These responses are mediated by chromophore-binding proteins that act as receptors in the transduction of the light signal for the regulation of specific metabolic or morphological

†Present address: Universidad Autónoma de San Luis Potosí, San Luis Potosí, Mexico.

‡Present address: Instituto Potosino de Investigación Científica y Tecnológica, A. C. San Luis Potosí, San Luis Potosí, Mexico.

§Present address: Escuela de Químico Farmacobiología, Universidad Michoacana de San Nicolás de Hidalgo, Morelia, Mich., Mexico.

Abbreviations: EST, expressed sequence tag; LRE, light-responsive element; WCC, white collar complex.

The microarray platform used in the experiments reported in this paper, and the corresponding information on the spotted genes, are available through Gene Expression Omnibus (accession no. GPL4189) from NCBI. programmes through the alteration of gene expression (Ma et al., 2001; Linden et al., 1997; Fankhauser, 2001).

In fungi, phototropism, the induction of carotenogenesis, the formation of reproductive structures, and resetting of the circadian clock are triggered by light (Gressel, 1983). Several elements associated with the molecular basis of these phenomena have been described. In Aspergillus nidulans conidiation induced by red light depends on the velvet gene (veA1). The product of the $v e A$ gene has been identified as an activator of sexual development as well as an inhibitor of asexual development; this response is, at least in part, dependent on a functional phytochrome (Adams et al., 1998; Blumenstein et al., 2005). Unfortunately, not much more is known about red light perception in fungi, even though phytochrome-encoding genes have been found in most sequenced fungal genomes, and two phytochromes from Neurospora crassa have been shown to fulfil all characteristics of active phytochromes (Froehlich et al., 2005). In $N$. crassa, blue light induces conidiation, carotenogenesis and phototropism, and regulates the circadian rhythm. The proteins white collar 1 and 2 (WC1 and WC-2) are essential for all these responses. WC-1 acts as photoreceptor and in combination with WC-2 transduces the light signal, activating the expression of a set genes 
required for the different responses (Froehlich et al., 2002; He et al., 2002). A group of early light-induced genes, showing transient expression patterns typical of adaptive responses, has been identified (Lewis et al., 2002). Among those genes, one encoding a secondary blue-light photoreceptor, VIVID, necessary for the adaptation to this stimulus, was found (Schwerdtfeger \& Linden, 2003). More complex light perception and regulation mechanisms have been described for higher eukaryotes. Plants, as sessile organisms that depend on sunlight for photosynthesis, have far more complex and specialized mechanisms that allow them to respond to specific quantities and qualities of light, or even combinations of different wavelengths. In the model plant Arabidopsis thaliana, two cryptochromes (CRY-1 and CRY-2), five phytochromes (PHY-A-E) and two phototropins (PHO-A and $\mathrm{PHO}-\mathrm{B}$ ) that regulate different developmental processes activated by light have been described (Briggs \& Huala, 1999; Briggs \& Christie, 2002; Fankhauser, 2001).

Trichoderma atroviride is a common soil fungus widely used as a biocontrol agent due to its capacity to parasitize phytopathogenic fungi of major agricultural importance. The application of $T$. atroviride in the field is based on the use of conidia, the products of asexual reproduction. It has been shown that conidiation is tightly regulated by light and nutrient availability in this fungus (Horwitz et al., 1985). In T. atroviride, a pulse of blue/UVA light induces the synchronous production of conidia situated at the colony perimeter where the pulse was received. The early physiological responses induced by light in Trichoderma viride include changes in protein phosphorylation patterns and membrane potential (Gresik et al., 1988, 1989), increases in the activity of adenylyl cyclase (Kolarova et al., 1992), as well as in the levels of cAMP and ATP (Gresik et al., 1988), and the accumulation of mRNA of the photolyase-encoding gene phr-1 (Berrocal-Tito et al., 2000). The promoter region of phr-1 contains an array of cis-acting elements similar to those defined for light-regulated genes in $N$. crassa (Berrocal-Tito et al., 2000). Recently, we reported the identification of two genes (blr-1 and $b l r-2)$ that are orthologues of the $N$. crassa $w c-1$ and $w c-2$. Both blr genes are essential for photoconidiation and light-induced expression of phr-1 (Casas-Flores et al., 2004).

For a comprehensive investigation aimed at understanding light regulation of gene expression and the reproductive process in T. atroviride, we carried out microarray analyses of expressed sequence tags (ESTs). Using this technology we determined the gene expression profile upon light induction of 1438 unigenes. We identified 40 light-regulated genes and analysed their dependence on the blr genes using the corresponding deletion mutants. In addition to the expected $b l r$-dependent response, we found a novel $b l r$-independent one, suggesting the existence of an additional light receptor. Sequence analysis of the light-responsive genes identified indicates that the initiation of the developmental programme leading to conidiation is accompanied by the activation of cell defence systems. Finally, we report the first evidence of red-light-regulated gene expression in fungi.

\section{METHODS}

Growth conditions, media and strains. Trichoderma atroviride wild-type strain IMI206040 and the $\Delta b l r-1$ and $\Delta b l r-2$ mutants were grown in total darkness on PDYCA medium (per litre: 39 g potato dextrose agar, $2 \mathrm{~g}$ yeast extract and $1.2 \mathrm{~g}$ casein hydrolysate medium, all from Difco) at $27^{\circ} \mathrm{C}$. Escherichia coli strains TOP $10 \mathrm{~F}^{\prime}$ and DH5 $\alpha$ (Invitrogen) were used for plasmid DNA transformation.

Photoinduction. T. atroviride cultures were grown in the dark for $48 \mathrm{~h}$ at $27^{\circ} \mathrm{C}$ on PDYCA plates and used a pre-inoculum. Mycelial plugs were then placed on a washed cellophane sheet overlaying a double layer of filter paper (an $8 \mathrm{~cm}$ disk of Whatman 50 was overlaid on a $7 \mathrm{~cm}$ disk of Whatman 1 filter paper in a Petri dish) soaked in $3 \mathrm{ml}$ PDYCB medium (per litre: $24 \mathrm{~g}$ potato dextrose broth, $2 \mathrm{~g}$ yeast extract and $1.2 \mathrm{~g}$ casein hydrolysate medium). Cultures were allowed to grow for a further $36 \mathrm{~h}$ in the dark, and then photoinduced basically as previously described (Berrocal-Tito et al., 1999). For blue light experiments, colonies were exposed to a light source consisting of two cool-white fluorescent tubes filtered with LEE filter no. 183 (fluence rate $5 \mu \mathrm{mol} \mathrm{m}^{-2} \mathrm{~s}^{-1}$ ) for $5 \mathrm{~min}$, and placed back in the dark at $27^{\circ} \mathrm{C}$ until mycelial samples were collected. At the indicated times, mycelia were scraped from the surface of the cellophane overlaying the filter paper under weak red light (LEE filter no. 106, fluence rate $0 \cdot 1 \mu \mathrm{mol} \mathrm{m} \mathrm{m}^{-2} \mathrm{~s}^{-1}$ ) and immediately frozen in liquid nitrogen for RNA extraction. For red light experiments, the procedure was the same, but light from the fluorescent lamps was filtered through an LEE filter no. 106 (fluence rate $\left.4 \cdot 8 \mu \mathrm{mol} \mathrm{m} \mathrm{m}^{-2} \mathrm{~s}^{-1}\right)$. LEE filters are a product of LEE filters USA and were purchased from Lighting System de Mexico.

For photoadaptation experiments, we followed the procedure described above for photoinduction, except that mycelia were kept illuminated until the samples were collected and frozen for RNA extraction.

Nucleic acid isolation and sequencing. Total RNA was isolated using a modified phenol-SDS method and Northern analysis was carried out using standard procedures (Sambrook et al., 1989). Ten micrograms of total RNA isolated from light induced mycelia was transferred onto nylon membranes (Amersham Biosciences). After transfer, the RNA was UV cross-linked (Strata linker; Hofer Scientific) to the membrane and hybridized to cDNA probes from light-regulated cDNA candidates obtained by PCR that were recovered from agarose gels using the QIAquick Spin Handbook protocol (Qiagen). Seventy-five nanograms of the cDNA was labelled with $\left[{ }^{32} \mathrm{P}\right] \mathrm{dCTP}$.

Plasmid DNA from colonies was prepared with the QIAPrep MiniPrep Kit (Qiagen), according to the instructions of the manufacturer. Samples were loaded on an ABI 377 DNA sequencer for automated sequence analysis.

Microarray construction. Two standard cDNA libraries were prepared, one obtained using mRNA extracted from T. atroviride mycelia induced by exposure to a $5 \mathrm{~min}$ pulse of blue light and placed back in the dark (from a pool of RNAs extracted 5 and 30 min after induction), and the second from mycelia grown in submerged cultures using Rhizoctonia solani cell walls as sole carbon source. Additionally, four subtractive cDNA libraries were constructed using the PCR-Select cDNA Subtraction System (Clontech) starting from T. atroviride RNA purified after exposure of the fungus to a $5 \mathrm{~min}$ pulse of blue light and collected 5 and $30 \mathrm{~min}$ after induction, and their corresponding dark controls, subtracting in both directions. A 
total of $5000 \mathrm{cDNA}$ clones from these libraries were sequenced to generate a collection of ESTs. From this collection, a set of 1425 unique genes (unigenes), together with 13 previously cloned genes (blr-1, blr-2, tpk-1, phr-1, tste-11, tste-12, tslt-2, tga-1, tvk-1, tnit-2, ech-42, prb-1 and pka-R) from T. atroviride and 3 negative control spots, the $A$. nidulans verA and aflR and pap-1 from A. thaliana (Lewis et al., 2002) were included on each array, yielding 1441 probe spots per array.

Of the 1425 ESTs that are represented in the T. atroviride microarray, 1332 were cloned into the vector pEXP-AD502 (Invitrogen) and the remainder (93 ESTs) from the cDNA subtractive libraries were cloned into the vector pCRII-Topo (Invitrogen). The insert sizes ranged from 0.5 to $3 \mathrm{~kb}$, with a mean insert size of $1.5 \mathrm{~kb}$. After assembly of the unigene set, cDNA inserts were amplified by PCR in a 96-well format using primers $5^{\prime}$-GCC/GCC/AGT/GTG/ATG-3' and $5^{\prime}$-GCC/AGT/ GTG/CTG/GAA/TTC- $3^{\prime}$ for the subtractive libraries and primers $5^{\prime}$ GTA/CAA/GAA/AGC/TGG/GTA/CG and 5'-GTA/CAA/AAA/AGC/ AGG/CTT/GTC/-3' for the ESTs cloned in pEXP-AD502. Plasmid DNA was used as a template for PCR amplification under the following conditions $\left({ }^{\circ} \mathrm{C} / t\right): 1$ cycle $94 / 5 \mathrm{~min}, 25$ cycles $94 / 30 \mathrm{~s}, 61-62 / 30 \mathrm{~s}, 72 /$ $3 \mathrm{~min}$ and one final cycle 72/7 $\mathrm{min}$ for both pCR2.1 and pEXP-AD502 respectively. To examine the quality and quantity of PCR products, these were separated on $2 \%$ agarose gels before and after purification. For purification, PCR products were submitted to ethanol precipitation in a 96-well filtration plate and resuspended in water to a final volume of $70 \mu \mathrm{l}$ at a concentration of $25-100 \mu \mathrm{g} \mathrm{ml}^{-1}$. SSC was added to the DNA isolated to a final concentration of $3 \times$ SSC. The design and printing of microarrays took place at the Laboratory for Functional Genomics of Texas A\&M University. Each spot was represented twice on the slide on polylysine-coated glass slides (CEL Associates) using a Gene Machines OmniGrid arrayer in 8 grids of 22 rows by 22 columns.

Microarray hybridization. Total RNA was isolated from colonies that were exposed to white light for $5 \mathrm{~min}$ (fluence rate $27 \mu \mathrm{mol} \mathrm{m} \mathrm{m}^{-2} \mathrm{~s}^{-1}$ ), and placed back in the dark at $27^{\circ} \mathrm{C}$ for $30 \mathrm{~min}$ (induced) and non-induced (kept at all times in the dark) using RNeasy kits (Qiagen). Ten micrograms of total RNA for each sample was reverse transcribed and labelled with Cy3 or Cy5 using the CyScribe First Strand cDNA Labelling Kit (Amersham Biosciences). The labelled products were purified with GFX purification columns (CyScribe GFX Purification Kit, Amersham Biosciences). The slides were placed in pre-hybridization solution $(1 \%$ BSA, $5 \times$ SSC and $0 \cdot 1 \%$ SDS at $45^{\circ} \mathrm{C}$ ) for $2 \mathrm{~h}$ to eliminate non-specific interactions, and then rinsed with $0 \cdot 1 \times \operatorname{SSC}\left(22-25^{\circ} \mathrm{C}\right.$ for $\left.5 \mathrm{~min}\right)$ and HPLCgrade water. Each slide was hybridized with a combination of untreated and treated labelled probes at $45^{\circ} \mathrm{C}$ for $14-16 \mathrm{~h}$ in a humidified hybridization chamber (Corning). After hybridization, the slides were washed once in solutions 1-4 (wash solution $1: 2 \times$ SSC, $0 \cdot 1 \%$ SDS at $45^{\circ} \mathrm{C}$; wash solution 2: $0 \cdot 1 \times$ SSC, $0 \cdot 1 \%$ SDS; wash solution 3: $0 \cdot 1 \times$ SSC; wash solution $4: 0 \cdot 01 \times$ SSC) for $5 \mathrm{~min}$ with gentle stirring/agitation. Washed slides were dried by centrifugation in a conical tube for $5 \mathrm{~min}$ at 1600 r.p.m.

Three independent replicates of each mycelial treatment, RNA isolation and labelling, and microarray hybridization were performed. To estimate 'system noise' that may be due to differences in Cy-dye labelling between samples, we performed a 'self-to-self' hybridization, where the same control sample was labelled separately with Cy5 and Cy3, and then hybridized. The microarray platform used in these experiments and the corresponding information on the spotted genes are available through Gene Expression Omnibus (accession no. GPL4189) from the National Center for Biotechnology Information (NCBI).

Microarray analysis. The slides were scanned using a confocal laser scanner (Chipreader, Virtek Vision) at a resolution of $10 \mu \mathrm{m}$ and the data files generated were collected and analysed with the ArrayPro Analyser software (Media Cybernetics). Data normalization was performed using the GeneSpring 6.1 software package (Silicon Genetics), applying the Cross-gene-error model in combination with a one-way ANOVA (significance level set at $P<0 \cdot 05$ ). The background fluorescence median values that were less than zero were set to zero and subjected to intensity-dependent LOWESS (locally weighted scatter plot smoother) normalization, in which $20 \%$ of the data was used for smoothing (Clevel \& Devlin 1998; Yang et al., 2001). This normalization was used to account for differences in overall intensity between slides. Each experimental result was interpreted as the mean of the three biological replicates and their corresponding swap replicate. Gene expression profiles were required to be present in all three of the datasets. A signal-to-control channel ratio equal to or higher than 1.8 and a probability $t$ test $P<0.05$ was defined as upregulation by the light stimulus. A signal-to-control channel ratio equal or lower than 0.667 (equivalent to at least a 1.8 -fold decrease) and a probability $t$ test $P<0.05$ was defined as downregulation.

\section{RESULTS}

\section{Identification of novel blue-light-regulated genes in $T$. atroviride}

In order to determine the global changes in gene expression triggered at early stages of photoconidiation we constructed two standard cDNA libraries and four blue light-dark subtractive libraries. Five thousand cDNA clones from these libraries, randomly chosen, were sequenced. A set of 1425 unique ESTs, derived from these data, plus 13 previously cloned genes (blr-1, blr-2, tpk-1, phr-1, tste-11, tste-12, tslt-2, tga-1, tvk-1, tnit-2, ech-42, prb-1 and pka-R) from $T$. atroviride and 3 negative controls were printed onto polylysine-coated glass slides, yielding 1441 probe spots per array. The microarrays were then used for the identification of genes that showed differential expression patterns after exposure of mycelia to a pulse of white light. For this purpose, the slides were hybridized with $\mathrm{Cy3}$ labelled cDNA, representing mRNA from mycelia kept in the dark, and Cy5-labelled cDNA, representing mRNA from mycelia collected $30 \mathrm{~min}$ after exposure to white light. We determined that 40 of the 1438 probe spots showed at least a $1 \cdot 8$-fold increase or decrease in mRNA levels after light exposure (Tables 1 and 2), representing $2 \cdot 8 \%$, of the genes analysed. Thirty genes (blu) were apparently upregulated (Table 1) and ten (bld), downregulated (Table 2). As expected, the control gene $p h r-1$ (blu-2), previously reported to be induced by light (Berrocal-Tito et al., 2000), was among the set of genes identified as light induced, thus validating our experimental procedures (Table 1).

All described light responses in both $T$. viride and $T$. atroviride are provoked by blue light (Gressel, 1983; Berrocal-Tito et al., 1999), and in N. crassa the whitecollar complex (WCC) regulates all known blue-light responses (Froehlich et al., 2002; He et al., 2002). In addition, all light-responsive genes characterized so far are upregulated by this stimulus (Lewis et al., 2002). Because our microarray analysis indicated that there were both upand downregulated genes, we decided to determine if the expression of the genes identified was triggered by blue light and if the observed changes in expression levels were 
Table 1. T. atroviride blue-light-upregulated genes

Listed are early light-responsive genes that show $>1 \cdot 8$-fold increased expression and a $P$ value of $<0 \cdot 05$. The genes are named according to the expression level determined using the GeneSpring 6.1 software package (Silicon Genetics). The sequences were blasted versus the 'nr' database of NCBI.

\begin{tabular}{|c|c|c|c|c|}
\hline Gene & Fold change & Hit (score in bits) & BLAST match (GenBank no.) & Organism \\
\hline blu-1 & $43 \cdot 47$ & $6 \cdot 00 \mathrm{E}-15(82)$ & GRG-1 protein (gil12718321) & N. crassa \\
\hline blu-2 & $37 \cdot 69$ & $0(1038)$ & DNA photolyase, PHR-1 & T. atroviride \\
\hline blu-3 & $15 \cdot 95$ & $3 \cdot 00 \mathrm{E}-35(150)$ & Hypothetical protein MG02302.4 (gil38108267) & Magnaporthe grisea $70-15$ \\
\hline$b l u-4$ & $15 \cdot 47$ & $1 \cdot 00 \mathrm{E}-19(99 \cdot 8)$ & Hypothetical protein FG05175.1 (gil42551045) & Gibberella zeae $\mathrm{PH}-1$ \\
\hline blu-5 & $10 \cdot 47$ & - & No hits found & - \\
\hline blu-6 & $10 \cdot 47$ & $1 \cdot 00 \mathrm{E}-26(121)$ & $\begin{array}{l}\text { Hypothetical protein; low similarity to a region of yeast } \\
\text { farnesyl cysteine: carboxyl methyltransferase (gil19075290) }\end{array}$ & Schizosaccharomyces pombe \\
\hline$b l u-7$ & $8 \cdot 85$ & $2 \cdot 00 \mathrm{E}-11(72 \cdot 8)$ & Predicted protein (gil42548056) & Gibberella zeae $\mathrm{PH}-1$ \\
\hline$b l u-8$ & $8 \cdot 55$ & - & No hits found & - \\
\hline blu-9 & $6 \cdot 93$ & $3 \cdot 00 \mathrm{E}-24(111)$ & Putative peptide transporter (gil19309404) & Aspergillus fumigatus \\
\hline blu-10 & $6 \cdot 89$ & $1 \cdot 00 \mathrm{E}-65(251)$ & Proline-specific permease (gil3929399) & Aspergillus nidulans \\
\hline blu-11 & $6 \cdot 65$ & $3 \cdot 00 \mathrm{E}-74(280)$ & Putative peptide transporter (gil19309404) & Aspergillus fumigatus \\
\hline blu-12 & $5 \cdot 08$ & - & No hits found & - \\
\hline blu-13 & $4 \cdot 46$ & $2 \cdot 00 \mathrm{E}-17(91 \cdot 7)$ & Putative fructosyl amino acid oxidase (gil19114083) & Schizosaccharomyces pombe \\
\hline blu-14 & $4 \cdot 43$ & - & No hits found & - \\
\hline blu-15 & $4 \cdot 18$ & $0(506)$ & Amino acid permease (gil462414) & T. atroviride \\
\hline blu-16 & $3 \cdot 86$ & $7 \cdot 00 \mathrm{E}-17(89 \cdot 4)$ & Putative dothistromin transporter (gil19386936) & Mycosphaerella pini \\
\hline blu-17 & $3 \cdot 59$ & $6 \cdot 00 \mathrm{E}-50(199)$ & Geranylgeranyl pyrophosphate synthetase (gil42545480) & Gibberella zeae $\mathrm{PH}-1$ \\
\hline blu-18 & $3 \cdot 16$ & $2 \cdot 00 \mathrm{E}-72(273)$ & Glucan $1,3-\beta$-glucosidase (gil8886891) & T. atroviride \\
\hline blu-19 & $3 \cdot 13$ & $1 \cdot 00 \mathrm{E}-19(99 \cdot 4)$ & Hypothetical protein FG02077.1 (gil42546865) & Gibberella zeae $\mathrm{PH}-1$ \\
\hline blu-20 & $3 \cdot 0$ & $7 \cdot 00 \mathrm{E}-43(175)$ & Kinesin (gil29421236) & Botryotinia fuckeliana \\
\hline blu-21 & $2 \cdot 84$ & $2 \cdot 00 \mathrm{E}-35(150)$ & Tripeptidylpeptidase 2 (gil42820809) & Aspergillus fumigatus \\
\hline blu-22 & $2 \cdot 68$ & $2 \cdot 00 \mathrm{E}-96(354)$ & Hypothetical protein FG10190.1 (gil42547190) & Gibberella zeae $\mathrm{PH}-1$ \\
\hline blu-23 & $2 \cdot 43$ & $3 \cdot 00 \mathrm{E}-17(90 \cdot 5)$ & Hypothetical protein FG09302.1 (gil42553232) & Gibberella zeae $\mathrm{PH}-1$ \\
\hline blu-24 & $2 \cdot 24$ & $2 \cdot 00 \mathrm{E}-51(204)$ & Putative allantoicase (gil19115407) & Schizosaccharomyces pombe \\
\hline blu-25 & $2 \cdot 16$ & $2 \cdot 00 \mathrm{E}-24(114)$ & Hydrophobin HFBI (gil1708378) & Trichoderma reesei \\
\hline blu-26 & $2 \cdot 09$ & $5 \cdot 00 \mathrm{E}-28(124)$ & Hypothetical protein FG06130.1 (gil42552229) & Gibberella zeae $\mathrm{PH}-1$ \\
\hline blu-27 & $1 \cdot 99$ & $8 \cdot 00 \mathrm{E}-76(285)$ & Hypothetical protein FG05871.1 (gil42551523) & Gibberella zeae $\mathrm{PH}-1$ \\
\hline blu-28 & $1 \cdot 99$ & $1 \cdot 00 \mathrm{E}-57(224)$ & Mannitol-1-phosphate dehydrogenase (gil22651499) & Aspergillus niger \\
\hline blu-29 & $1 \cdot 92$ & $0(597)$ & Monosaccharide transporter (gil27461189) & Aspergillus niger \\
\hline blu-30 & $1 \cdot 85$ & $2 \cdot 00 \mathrm{E}-25(115)$ & Glucoamylase (gil32414953) & Neurospora crassa \\
\hline
\end{tabular}

transient. For this purpose, T. atroviride $\Delta b l r-1, \Delta b l r-2$ and wild-type strains were exposed to a pulse of blue light, samples were collected at different time points after the pulse, and gene expression was analysed by Northern blotting. From 17 induced genes selected, the expression pattern of 14 of them confirmed the results obtained from the microarray analysis, including the previously characterized gene phr-1 (Figs 1 and 2). The three remaining genes showed no detectable mRNA levels. In the case of the downregulated genes, we selected six for this type of analysis; the expression of five of them was confirmed and one produced no detectable signal (Figs 1-3).

\section{The BLR complex mediates positive and negative regulation of gene expression}

As seen in Fig. 1, we identified by Northern analysis nine genes whose expression was induced by blue light in a
BLR-dependent fashion. The induction of these genes was transient, similar to what has been described for phr-1 (blu2); the expression pattern observed indicates that the corresponding transcript starts accumulating $5 \mathrm{~min}$ after the light pulse, reaching maximum induction at $30 \mathrm{~min}$ and decreasing by $120 \mathrm{~min}$ after exposure to light. Two groups of genes can be clearly separated by their basal levels of expression: those that are apparently not expressed in the dark (phr-1, blu-1, blu-3, blu-6, blu-7 and blu-13), and those with detectable levels of expression even in the dark (blu-5, blu-8, blu-16 and blu-17). Similar transient changes in gene expression have been described for early light-induced genes in N. crassa (Sommer et al., 1989).

Additionally, we determined that the expression of bld-2 and bld -3 is repressed by blue light in a BLR-dependent fashion. These genes showed high levels of expression when the wildtype strain was grown in the dark, and this level was not 
Table 2. Blue-light-downregulated genes from T. atroviride

Listed are early light-responsive genes that show $>1 \cdot 8$-fold decreased expression and a $P$ value of $<0 \cdot 05$. The genes are named according to the expression level determined using the GeneSpring 6.1 software package (Silicon Genetics). The sequences were blasted versus the 'nr' database of NCBI.

\begin{tabular}{|c|c|c|c|c|}
\hline Gene & $\begin{array}{l}\text { Fold } \\
\text { change }\end{array}$ & Hit (score in bits) & BLAST match (GenBank no.) & Organism \\
\hline bld-1 & $0 \cdot 24$ & $8 \cdot 00 \mathrm{E}-48(192)$ & Polyketide synthase (gil40806905) & Gibberella moniliformis \\
\hline bld-3 & $0 \cdot 37$ & $4 \cdot 00 \mathrm{E}-11(70 \cdot 1)$ & Protein localized to COPII-coated vesicles (gil6323573) & Saccharomyces cerevisiae \\
\hline bld-4 & $0 \cdot 43$ & $2 \cdot 00 \mathrm{E}-67(256)$ & Flavohaemoglobin (gil3551511) & Fusarium oxysporum \\
\hline bld -5 & $0 \cdot 44$ & $6 \cdot 00 \mathrm{E}-95(304)$ & Putative INO1 myo-inositol-1-phosphate synthase (gil34484375) & Aspergillus niger \\
\hline bld-7 & $0 \cdot 48$ & $1 \cdot 00 \mathrm{E}-100(411)$ & ATP-citrate-lyase (gil7159697) & Gibberella pulicaris \\
\hline bld-8 & $0 \cdot 49$ & $4 \cdot 00 \mathrm{E}-26(120)$ & Isoamyl alcohol oxidase (gil10119790) & Aspergillus oryzae \\
\hline bld -9 & $0 \cdot 49$ & $2 \cdot 00 \mathrm{E}-56(220)$ & $\begin{array}{l}\text { Probable thioredoxin peroxidase, mitochondrial isoform } \\
\text { (gil6319407) }\end{array}$ & Saccharomyces cerevisiae \\
\hline bld-10 & $0 \cdot 53$ & $2 \cdot 00 \mathrm{E}-54(214)$ & $\begin{array}{l}\text { Putative GTPase that associates with pre-60S ribosomal subunits } \\
\text { (gil6324381) }\end{array}$ & Saccharomyces cerevisiae \\
\hline
\end{tabular}

modified upon exposure to light of the $\Delta b l r-1$ and $\Delta b l r-2$ mutants. However, exposure of the wild-type strain to blue light resulted in decreasing levels of the corresponding transcripts that paralleled the induction pattern of $p h r-1$ and blu-1, $-3,-5,-6,-7,-8,-13,-16$ and -17 (Fig. 1). These data suggest that the $T$. atroviride BLR-1 and BLR-2 proteins participate in the repression of blue-light-regulated genes. The observed changes in expression level of this subset of genes are clearly dependent on the presence of functional $b l r-1$ and $b l r-2$. Thus, our data strongly support the notion that BLR-1 and BLR-2 participate as a complex in transcriptional regulation of blue-light-responsive genes.

\section{BLR-independent blue-light-regulated gene expression}

Casas-Flores et al. (2004) proposed that BLR-1 is the $T$. atroviride blue/UVA photoreceptor and demonstrated that BLR- 1 and 2 are essential for the regulation of the expression of phr-1 and light-induced conidiation. However, pharmacological studies had suggested the existence in T. atroviride of a divergent light signal transduction cascade or an alternative blue light perception pathway, which could be associated with cAMP (Berrocal-Tito et al., 2000). In this context, using the same approach we identified by Northern analysis two light-induced genes (blu- 4 and $b l u-15)$ and one
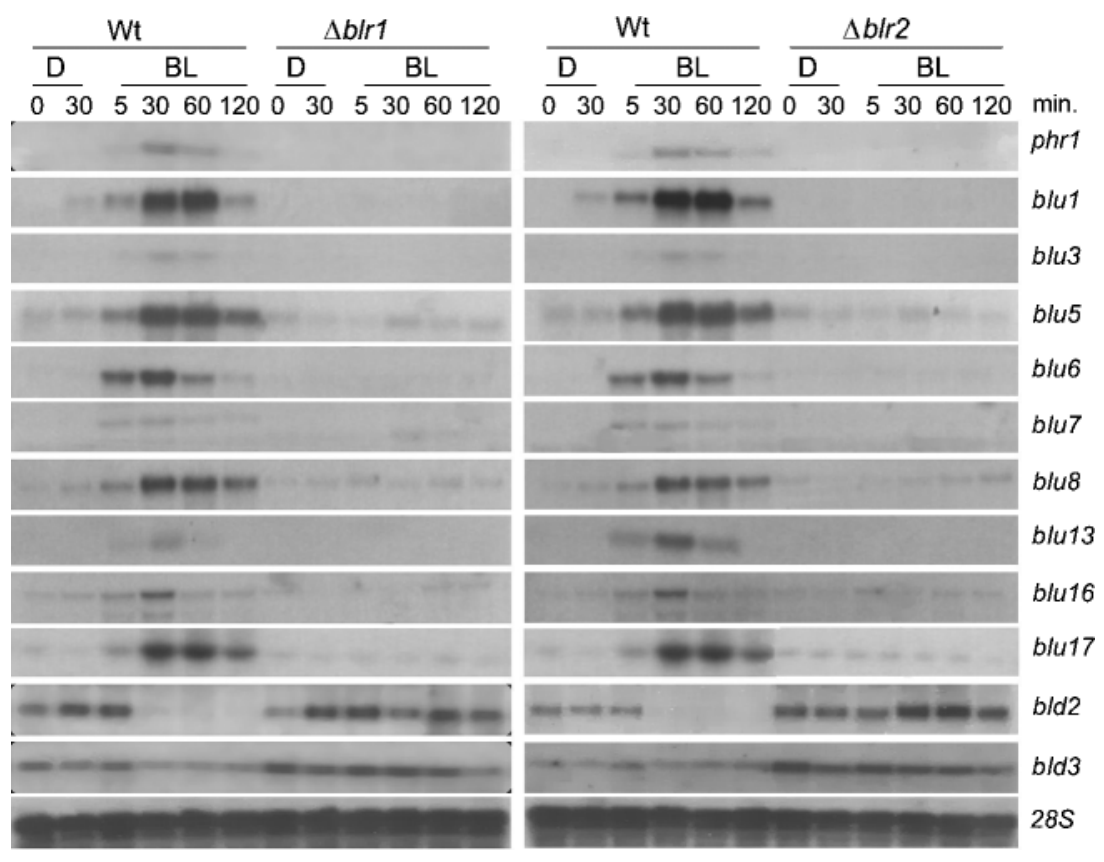

Fig. 1. BLR-dependent expression of bluelight-regulated genes: Northern blot analysis of $10 \mu \mathrm{g}$ total RNA isolated from mycelia grown in the dark (D) or exposed to a pulse of blue light $(\mathrm{BL})$ of the wild-type $(\mathrm{Wt}), \Delta b / r-1$ and $\Delta b / r-2$ strains. RNA was extracted at the indicated times $(\mathrm{min})$ after a $5 \mathrm{~min}$ light pulse. Blots were sequentially hybridized with ${ }^{32} \mathrm{P}$ labelled probes of the cDNA clones of the indicated genes. Hybridization with $28 \mathrm{~S}$ rRNA probe was used as loading control. 


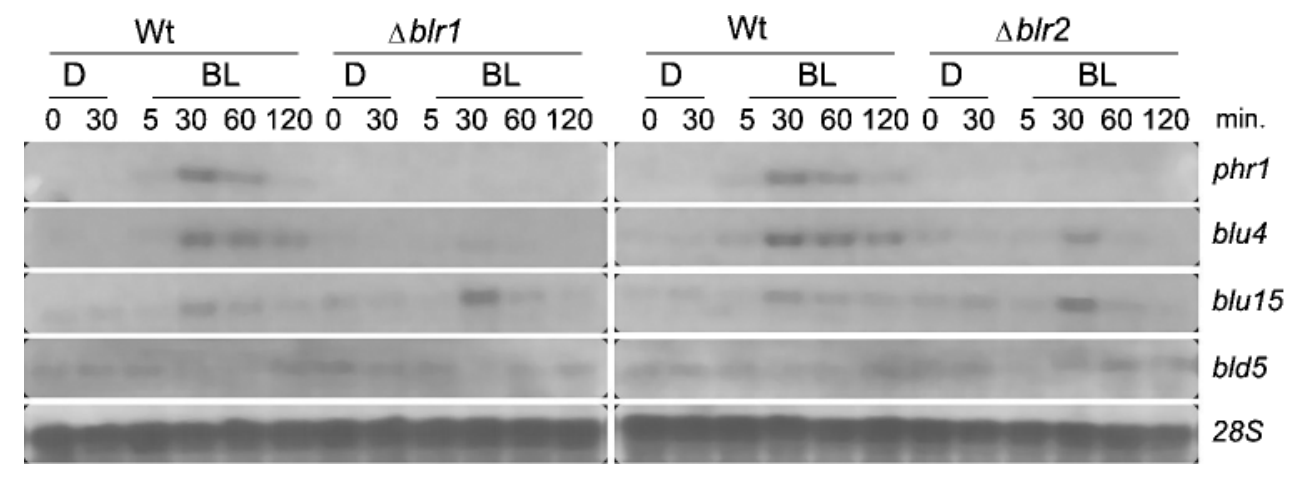

Fig. 2. BLR-independent blue-light-regulated gene expression: Northern blot analysis of $10 \mu \mathrm{g}$ total RNA isolated from mycelia grown in the dark (D) or exposed to a pulse of blue light (BL) of the wild-type (Wt), $\Delta b / r-1$ and $\Delta b / r-2$ strains. RNA was extracted at the indicated times ( $\mathrm{min}$ ) after a $5 \mathrm{~min}$ light pulse. Blots were sequentially hybridized with ${ }^{32} \mathrm{P}$-labelled probes of the cDNA clones of the indicated genes. Hybridization with $28 \mathrm{~S}$ rRNA probe was used as loading control.

light-repressed gene (bld-5) whose behaviour is independent of blr-1 and blr-2 (Fig. 2). Similarly to the BLRdependent genes, their expression pattern shows that the observed changes in gene expression are transient (Fig. 2). In contrast to the pattern of the BLR-dependent genes, at least in the case of two of the induced genes, there are clearly detectable levels of expression in the dark, and the light repression of bld-5 is partial. Additionally, an apparent derepression effect of the $b l u-15$ gene related to the loss of function of the blr genes is observed: compare the light induction of $b l u-15$ in the wild-type versus mutant strains in Fig. 2. However, the abundance of blu-4 mRNA is higher after photoinduction in the wild-type strain as compared with the $\Delta b l r$ mutants (Fig. 2). A similar effect has been observed in the transcriptional activation of the $N$. crassa genes con-5 and con-10 in response to nitrogen limitation in the $w c-1$ and $w c-2$ mutants (Sokolovsky et al., 1992). These results indicate the existence of a blue-light perception pathway independent of the BLR-1 and BLR-2 proteins, which exerts transcriptional regulation of gene expression in parallel to that controlled by the BLR complex.

The expression analysis of $b l u-11, b l u-29, b l d-6$ and bld-8 showed less evident changes when light and dark conditions were compared in the wild-type strain. Such changes were greater in the $\Delta b l r$ mutant strains (Fig. 3). Interestingly, in all cases, $5 \mathrm{~min}$ after exposure of the wild-type to light, the effect was the opposite of that expected from the microarray analysis, which was carried out at a single time point (30 min). In the case of blu-11 and blu-29, $5 \mathrm{~min}$ after exposure to the pulse of blue light there is a clear decrease in the corresponding level of mRNA, as compared to the dark control. Similarly, in the case of bld-6 and bld- 8 there is an increase of the corresponding mRNA levels at this time

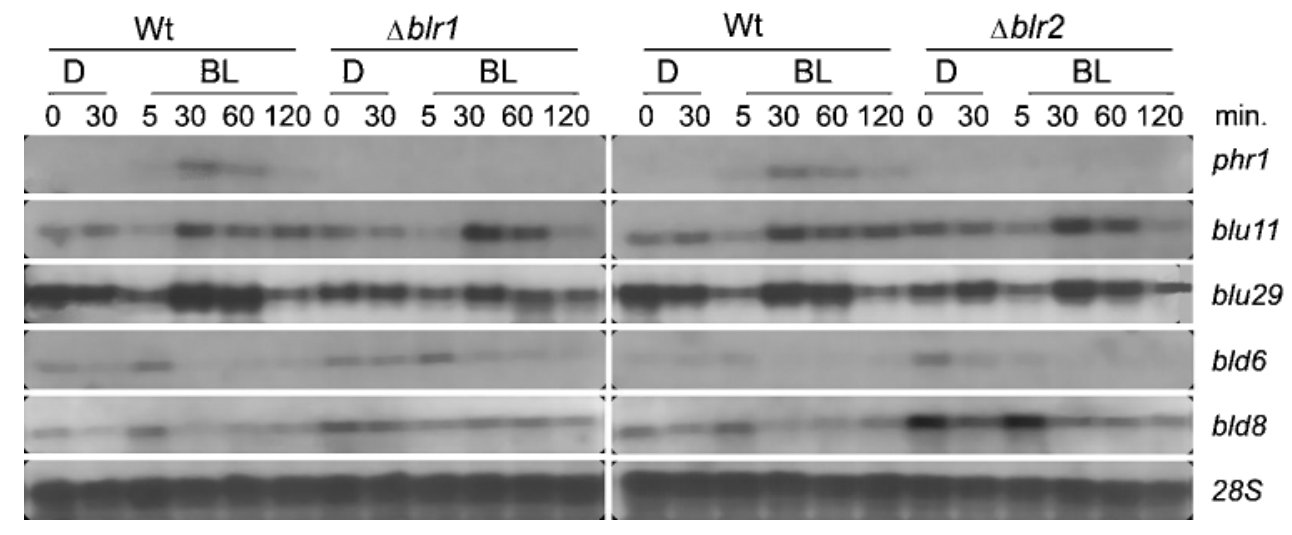

Fig. 3. BLR-modulated gene expression of blue-light-responsive genes: Northern blot analysis of $10 \mu \mathrm{g}$ total RNA isolated from mycelia grown in the dark (D) or exposed to a pulse of blue light (BL) of the wild-type (Wt), $\Delta b / r-1$ and $\Delta b / r-2$ strains. RNA was extracted at the indicated times $(\mathrm{min})$ after a $5 \mathrm{~min}$ light pulse. Blots were sequentially hybridized with ${ }^{32} \mathrm{P}-\mathrm{labelled}$ probes of the cDNA clones of the indicated genes. Hybridization with $28 \mathrm{~S}$ rRNA probe was used as loading control. 
point. Such an effect can still be observed in both $\Delta b l r$ mutants for blu-11 and blu-29.

\section{Light-responsive genes are subject to photoadaptation}

Normally responses to environmental stimuli are controlled in such a way that organisms are able to adapt to them. Such is the case for light-induced gene expression in Neurospora crassa. (Schwerdtfeger \& Linden, 2003). We therefore tested if the observed response to blue light was subject to photoadaptation. As seen in Fig. 4, the transcript levels of the genes blu-1, blu-3, blu-4, blu-8 and blu-16 reached a maximum after $60 \mathrm{~min}$ of continuous exposure to blue light, and decreased after $240 \mathrm{~min}$. This response was similar to what has been previously described for phr-1 (BerrocalTito et al., 2000), and indicated that this set of genes is subject to photoadaptation. In the case of $b l u-17$, we observed the maximum level of expression after $30 \mathrm{~min}$ of exposure to light, with a decrease from then on. However, the drop in transcript level of blu-17 was not as clear as that observed for the rest of the genes. In the case of the only repressed gene tested (bld-2), we observed a minimum of expression only after $240 \mathrm{~min}$, the last time point considered in our assay. Thus, we did not observe a photoadaptative response, but cannot discard the possibility of this gene going back to its level of expression in the dark after a more prolonged exposure to light.

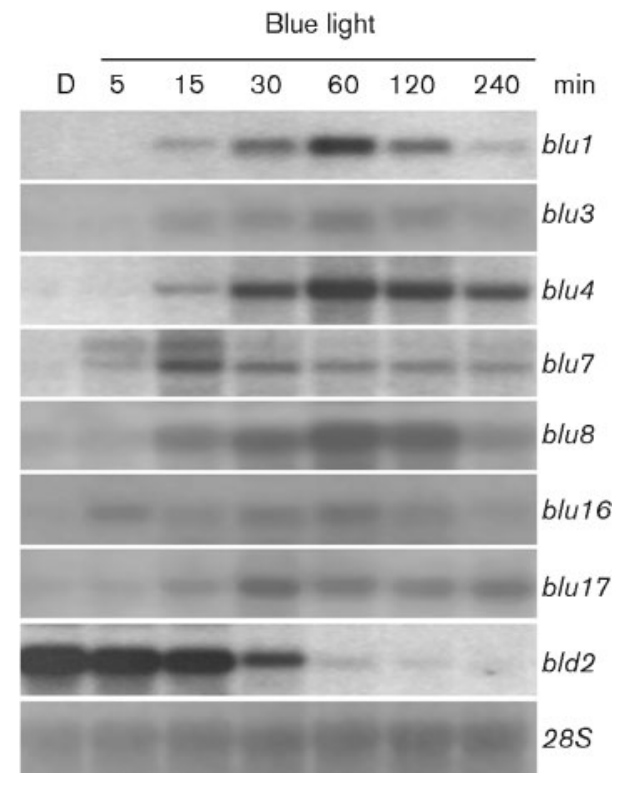

Fig. 4. Photoadaptation of gene expression to blue light: Northern blot analysis of $10 \mu \mathrm{g}$ total RNA isolated from mycelia of the wild-type strain grown in the dark (D) or exposed to blue light for the indicated times. Blots were sequentially hybridized with ${ }^{32} \mathrm{P}$-labelled probes of the cDNA clones of the indicated genes. Hybridization with $28 \mathrm{~S}$ rRNA probe was used as loading control.

\section{Red-light-induced gene expression}

Based on the observed effect of light on gene expression even in the absence of the blr genes and the previously observed mycelial growth inhibition effect of red light in T. atroviride (Casas-Flores et al., 2004), and because of the recent findings on the effect of red light in sexual development in $A$. nidulans (Blumenstein et al., 2005), we decided to determine if red light had any effect on the expression of any of the genes analysed here. As shown in Fig. 5, there was a clear increase of transcript levels of the genes blu-4, blu-15 and bld-8 after exposure of T. atroviride to a $5 \mathrm{~min}$ pulse of red light. All three genes reached a maximum of expression 15 min after the light pulse. Interestingly, two different transcripts were observed for $b l d-8$, with a stronger effect of red light on the larger transcript. In contrast, there was no effect of red light on the expression of the BLR-dependent gene blu-17. The expression of none of the rest of the 19 genes examined here was significantly affected by exposure of $T$. atroviride to a pulse of red light, as compared to their expression in the dark (data not shown).

\section{Putative regulatory elements controlling light-responsive genes}

Recently, He \& Liu (2005) showed that in N. crassa the light induction of immediate light-inducible genes is regulated through binding to their promoter light-response elements (LREs) of light-activated WCCs, and proposed a consensus sequence (GATNC----CGATN) for LREs. We decided to investigate if similar motifs were present in the promoter region of the T. atroviride light-responsive genes. As we have recently found that several of the blu genes are also induced by light in Trichoderma reesei (unpublished data), we obtained the sequence of the promoter region of the

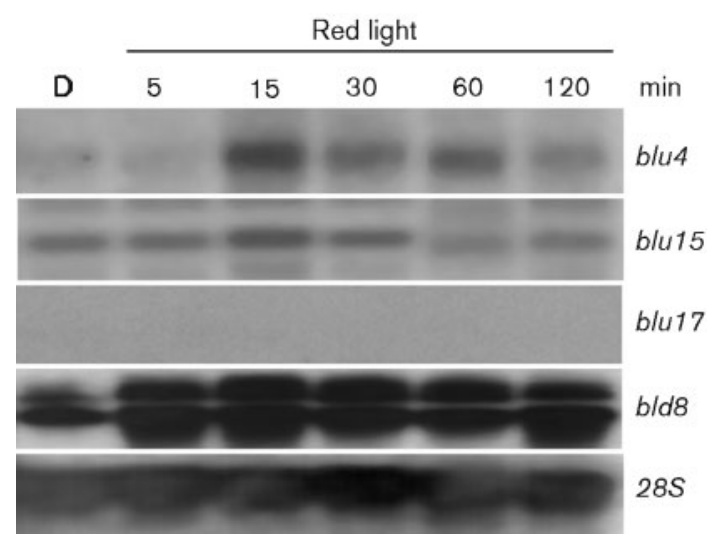

Fig. 5. Red-light-induced gene expression: Northern blot analysis of $10 \mu \mathrm{g}$ total RNA extracted from mycelia of the wild-type strain at the indicated times ( $\mathrm{min}$ ) after a $5 \mathrm{~min}$ pulse of red light or grown in the dark (D). Blots were sequentially hybridized with ${ }^{32} \mathrm{P}$-labelled probes of the cDNA clones of the indicated genes. Hybridization with $28 \mathrm{~S}$ rRNA probe was used as loading control. 
homologues of the light-responsive genes from the T. reesei genome sequence (http://gsphere.lanl.gov/trire1/trire1. home.html). We found LREs in most of the light-responsive genes detected in the microarray analysis, with varying distances between the GATNC and CGATN sequences, except that the nucleotide $\mathrm{N}$ was mostly not the same in both repeats. As shown in Table 3, all the BLR-dependent genes had at least a perfect match with the consensus repeat sequence; in several cases we found the LRE repeated twice in the promoter, and found other GATA sequences associated with it. Furthermore, among the genes whose expression was not tested by Northern blotting, 13 had perfect LREs, whereas within the BLR-independent genes only blu- 4 had a perfect LRE. These data suggest that most of the light-responsive genes identified are under the control of the BLR complex.

It has also recently been described that light stimulates cellulase gene expression in T. reesei (Schmoll et al., 2005). Binding sites for fungal GATA factors such as BLR-1 and BLR-2 are present in the promoters of $c b h-1, c b h-2$, and $e n v-$ 1. However, the same group identified two putative proteinbinding motifs, envoy upstream motifs 1 and 2, EUM1 (CTGTGC--CTGTGC) and EUM 2 (ACCTTGAC), in the promoters of $e n v-1, b l r-1, b l r-2$ and $c b h-1$, suggesting that such elements might be involved in light activation of gene expression. We found imperfect EUM1-binding sequences in four of 38 promoters analysed. In the promoter of blu-24 we found a perfect EUM1-binding motif, but the two repeats were found 169 bases apart. The EUM2-binding motif was found only in one of the blue-light-downregulated genes (bld-3).

\section{DISCUSSION}

All known responses to blue light in $N$. crassa are regulated by the WC- 1 and WC-2 transcription-activating factors; mutations in either of the corresponding genes result in total 'blindness' (Linden \& Macino, 1997; Ballario et al., 1996). Even though genes encoding proteins similar to cryptochromes and phytochromes have been found in the N. crassa genome, WC-1 appears to be the functional primary blue light receptor (He et al., 2002; Froehlich et al., 2002). We have previously demonstrated the key role of the $w c-1$ and $w c-2$ orthologues from $T$. atroviride (blr-1 and blr-2) in photoconidiation and in the transcription of the photolyaseencoding gene phr-1 (Casas-Flores et al., 2004). Here, we used microarrays containing approximately one-fifth of the $T$. atroviride genome for the identification of early lightresponse genes; $2 \cdot 8 \%$ of the genes analysed by microarrays responded to light, showing transient patterns of expression similar to that described for phr-1. In N. crassa, a similar number of genes $(3 \%)$ are activated by blue light, with no evidence of repression at the transcriptional level associated with the stimulus (Lewis et al., 2002). Interestingly, only two of the T. atroviride genes (blu-1 and blu-17) induced by light have been found to be light inducible in $N$. crassa. In contrast, analyses of the expression of 6000 genes in the model plant $A$. thaliana showed that $34 \%$ of the genes were regulated by light (Ma et al., 2001). However, a global analysis of the expression of the A. thaliana genome identified only 100 genes activated and 7 genes repressed by UVB as an early response to exposure to light (Ulm et al., 2004).

In this work, we demonstrated that at least ten genes are induced and two are repressed by light in a BLR-dependent

Table 3. Promoter sequence analysis of BLR-dependent genes

For the analysis the T. reesei orthologues of the light-responsive genes were identified, except for blu-2, which corresponds to the T. atroviride gene. The analysis was carried out using a $1000 \mathrm{bp}$ sequence upstream from the putative ORF of the corresponding gene. The table shows only the position, relative to the start of the ORF, and sequence of the putative LREs identified in the promoters of genes whose expression was validated by Northern blotting. Underlined sequences indicate perfect matches to the proposed consensus.

\begin{tabular}{|c|c|c|}
\hline Gene & LRE sequence & EUM1/EUM2-binding motif \\
\hline$b l u-2$ & $\overline{\operatorname{GATAC}}(\mathrm{N})_{42} \overline{\mathrm{CGATC}}(-181)$ & None found \\
\hline blu-5 & $\operatorname{GATAC}(\mathrm{N})_{50} \operatorname{GATG}(\mathrm{N})_{11} \operatorname{GATG}(\mathrm{N})_{4} \operatorname{CGATG}(-751)$ & None found \\
\hline blu-6 & $\overline{\text { GATCC }}(\mathrm{N})_{6}$ CGATT $(N)_{109} /$ GATGC $(N)_{61}$ CGATC $(-293)$ & $\begin{array}{l}\text { CTGTGC }(\mathrm{N}){ }_{15} \text { CTGTGG } \\
(-627) / \text { Not found }\end{array}$ \\
\hline$b l u-8$ & $\overline{\text { Unknown }}$ & Unknown \\
\hline blu-13 & $\operatorname{GATTC}(\mathrm{N})_{24} \operatorname{CGATG}(-715)$ & None found \\
\hline blu-16 & $\overline{\operatorname{GATCC}}(\mathrm{N})_{54} \overline{\operatorname{GGATG}} \mathrm{G}(\mathrm{N})_{144} \operatorname{CGATA}(\mathrm{N})_{48} \operatorname{GATC}(\mathrm{N}){ }_{17} \operatorname{TGATG}(\mathrm{N}){ }_{13} \operatorname{GATGC}(\mathrm{N})_{132} \operatorname{CGATG}(-437)$ & None found \\
\hline blu-17 & $\overline{\operatorname{GATGC}}(\mathrm{N})_{26}$ CGATT $(-811)$ & None found \\
\hline bld-2 & 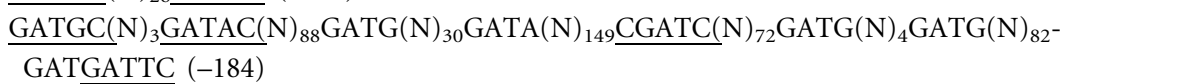 & None found \\
\hline
\end{tabular}


fashion (Fig. 1). These data provide evidence for a dual role of the BLR proteins, namely transcriptional activation and repression of gene expression. In addition, the dependence of this response on both BLR-1 and 2 supports their participation as a complex (Casas-Flores et al., 2004). The WC- 1 and WC-2 proteins of N. crassa act as a heterodimeric complex in the induction of transcription of light-activated genes. However, light-dependent negative control of gene expression by the WCC has not been documented. In this context, an interesting finding was that the response to light of four induced and three repressed genes was independent of the BLR proteins. Additionally, we were able to demonstrate that at least some of the blue-light-induced genes are subject to photoadaptation. Such a phenomenon has previously been described in $N$. crassa, where the participation of the photoreceptor VIVID is essential (Schwerdtfeger \& Linden, 2003). A protein (ENVOY) similar to VIVID has recently been described in T. reesei, a close relative of $T$. atroviride. However, transformation with envoy of a vivid mutant of $N$. crassa did not complement the mutation (Schmoll et al., 2005). Whether an orthologue of ENVOY exists in T. atroviride and whether it plays any role in photoadaptation in Trichoderma spp. remain to be proven.

Molecular and pharmacological data suggest the participation of the cAMP pathway in photoconidiation (BerrocalTito et al., 2000; Gresik et al., 1988; Kolarova et al., 1992; Rocha-Ramírez et al., 2002). Additionally, light-induced phosphorylation of cytosolic proteins, in vitro, has been described in T. viride. Such phosphorylation activity appears to be membrane associated and can be mimicked by the addition of cAMP (Gresik et al., 1989). The WC-1 protein is the photoreceptor in N. crassa and its subcellular localization is nuclear, where it complexes with WC-2 to regulate all light responses (Schwerdtfeger \& Linden, 2000). Similarly, the BLR-1 protein contains the LOV domain essential to carry out the photoperception, and has a nuclear localization signal, as BLR-2 does (Casas-Flores et al., 2004). These data suggest that the photoperception pathway independent of the BLR proteins might be associated with a pathway utilizing cAMP as second messenger. Further evidence supporting this hypothesis comes from the fact that protein kinase A activity is induced by light even in $\Delta b l r-1$ and $\Delta b l r$ 2 mutants (Casas-Flores et al., 2006). We identified several light-responsive genes independent of the BLRs, which show a pattern of expression similar to that of the BLR-dependent genes (Fig. 2). This molecular evidence provided further support for the existence of an alternative light-signalling pathway independent of the BLR proteins. In this context, here we have shown that there is a clear increase of transcript levels of the genes $b l u-4, b l u-15$ and $b l d-8$ after exposure of $T$. atroviride to a pulse of red light (Fig. 5). The observed effect of blue light on blu-4 and blu-15 might in part be explained by the fact that the filter used to obtain blue light allows some red light to pass through. However, the effect of blue light was much stronger in the wild-type strain than in the blr mutants, suggesting that both genes are under the control of both blue and red light. Furthermore, the expression of $b l d-8$ is negatively affected by blue light, whereas application of a pulse of red light resulted in clearly increased levels of expression of this gene. Thus, our data suggest a crosstalk between the blue and red light perception pathways. Such a crosstalk has clearly been established in plants, where phytochromes perceive red light (DeBlasio et al., 2003; Folta \& Spalding, 2001). Genes encoding phytochromes have been found in several fungal genomes, including that of $T$. reesei. Two phytochromes have been deeply studied in N. crassa, although no phenotype has been observed in the corresponding mutants, and more recently, a role for a phytochrome in sexual development has been established in A. nidulans (Blumenstein et al., 2005; Froehlich et al., 2005). Thus, it is likely that the red light responses observed in T. atroviride are mediated by a phytochrome.

Different DNA elements present in the promoter of lightresponsive genes have been proposed to be involved in their light-dependent regulation (He \& Liu 2005; Schmoll et al., 2005). We searched for the three proposed consensus sequences LRE, EUM1 and EUM2. We found motifs present in the promoters of the $T$. reesei genes that resemble very closely the LREs in all BLR-dependent light-responsive genes (Table 3). In contrast, we found imperfect EUM1binding sequences in only four of 38 promoters analysed. Therefore, if EUM1 and EUM2 play any role in regulating light-activated gene expression in T. atroviride it is unlikely that it is an important one in the response of immediate light-inducible genes. Our data support the evidence found in N. crassa indicating that the GATNC----CGATN repeats play a major role in regulating activation of gene expression in response to light (He \& Liu, 2005).

A BLAST analysis of the deduced protein sequences of the genes analysed against the non-redundant 'nr' polypeptide database was carried out (summarized in Tables 1 and 2). In addition, most of the deduced proteins of the light-regulated genes showed homology to proteins found in the $N$. crassa genome. Among these proteins, the sequence derived from blu-1 was found to be highly similar to Grg-1. The regulation by light and development of blu-1 is similar to that reported for grg-1 in N. crassa (Wang et al., 1994). The deduced protein sequence of blu-4 shows significant homology (9E-9) to a protein related to the chitinase-3 precursor protein from $N$. crassa. In addition, BLU-11 showed high similarity (3E-49) to the peptide transporter TRA2, BLU-29 to a monosaccharide transporter (1E-100), BLU-15 to the amino acid-permease NAAP1 $(\mathrm{E}=0)$ and BLU-16 to the DHA14-like major facilitator efflux transporter (MFS transporter). Among the downregulated genes we found that bld-2 encodes a protein with high similarity $(6 \mathrm{E}-14)$ to a probable L-xylulose reductase and bld-10 encodes a protein related to GTPbinding proteins (4E-73), whereas blu-15 and blu-18 correspond to genes encoding an amino acid transporter (inda1) and a glucanase $(g l u c 78)$, previously reported for $T$. atroviride (formerly T. harzianum) and found to be induced during simulated mycoparasitism (Vasseur et al., 1995). 
Several of the light-responsive genes identified here did not produce any significant hit with the sequences reported in any public database, while others had matches to hypothetical proteins. Thus, we decided to carry out a detailed sequence analysis in silico to look for domains and motifs, and to find possible subcellular localization signals (Table 4).

The role of PHR-1 in protection from DNA damage by light, through the photoreactivation of pyrimidine cyclobutane dimers (Sancar \& Sancar, 1988), has led to the suggestion that blue/UVA light is an environmental cue indicative of stress. The results of the in silico analysis (Table 4) allowed us to determine that the protein deduced from the gene blu3 has a conserved domain (ENDO3c/Nth) present in endonuclease III, an enzyme that plays a major role in excision repair (Sancar \& Sancar, 1988). Both BLU-3 and BLU-2 (PHR-1) have nuclear and mitochondrial localization signals, where their activities would be important in the protection of DNA from possible damage provoked by light. Another protein that might be involved in the repair of DNA damage is BLU-14, which has a nuclear localization signal, and shows low homology to conserved motifs found in the proteins UVS2 of N. crassa and RAD18 of Saccharomyces cerevisiae (Tomita et al., 1993).

Another mechanism that helps in the protection against the potentially harmful effects of light is the production and accumulation of pigments that function as a solar screen, reducing the incidence of light on photosensitive cell components. In this context, blu-17 encodes a geranylgeranyl pyrophosphate synthase (GGPPS), with strong similarity to $\mathrm{Al}-3$, previously reported as induced by light (Harding \& Turner, 1981) that carries out the first step in the synthesis of carotenoids (Carattoli et al., 1991). Mutation of any of the Neurospora al genes results in an albino phenotype; such mutants are more sensitive to UVB light and oxidative stress (Linden, 2002). If a carotenoid biosynthesis pathway is activated by light in $T$. atroviride it is not obviously reflected in the accumulation of pigments in the mycelium upon exposure to light. However, GGPPS, as a prenyltransferase, could be involved in the synthesis of a variety of metabolites with important roles in cell metabolism (Glomset et al., 1990). Interestingly, the gene bld-1, encoding a putative polyketide synthase that may be involved in the first step in the biosynthesis of melanin, which protects cells from the harmful effect of UV irradiation and oxidative stress, is repressed rather than induced by light (Langfelder et al., 2003).

The key regulatory factors involved in photoconidiation in T. atroviride remain unknown. Among the set of genes found in our analysis, at least three encode proteins with nuclear localization signals and possess characteristics that make them potential transcriptional regulators. BLU-7

Table 4. In silico analysis of deduced protein sequences

The programs PFAM, PROSITE and SMART (http://myhits.isb-sib.ch/cgi-bin/motif_scan and http://www.ncbi.nlm.nih.gov/blast/) were used to look for domains and motifs, and PSORT (http://www.genome.jp/SIT/) to find possible subcellular localization signals.

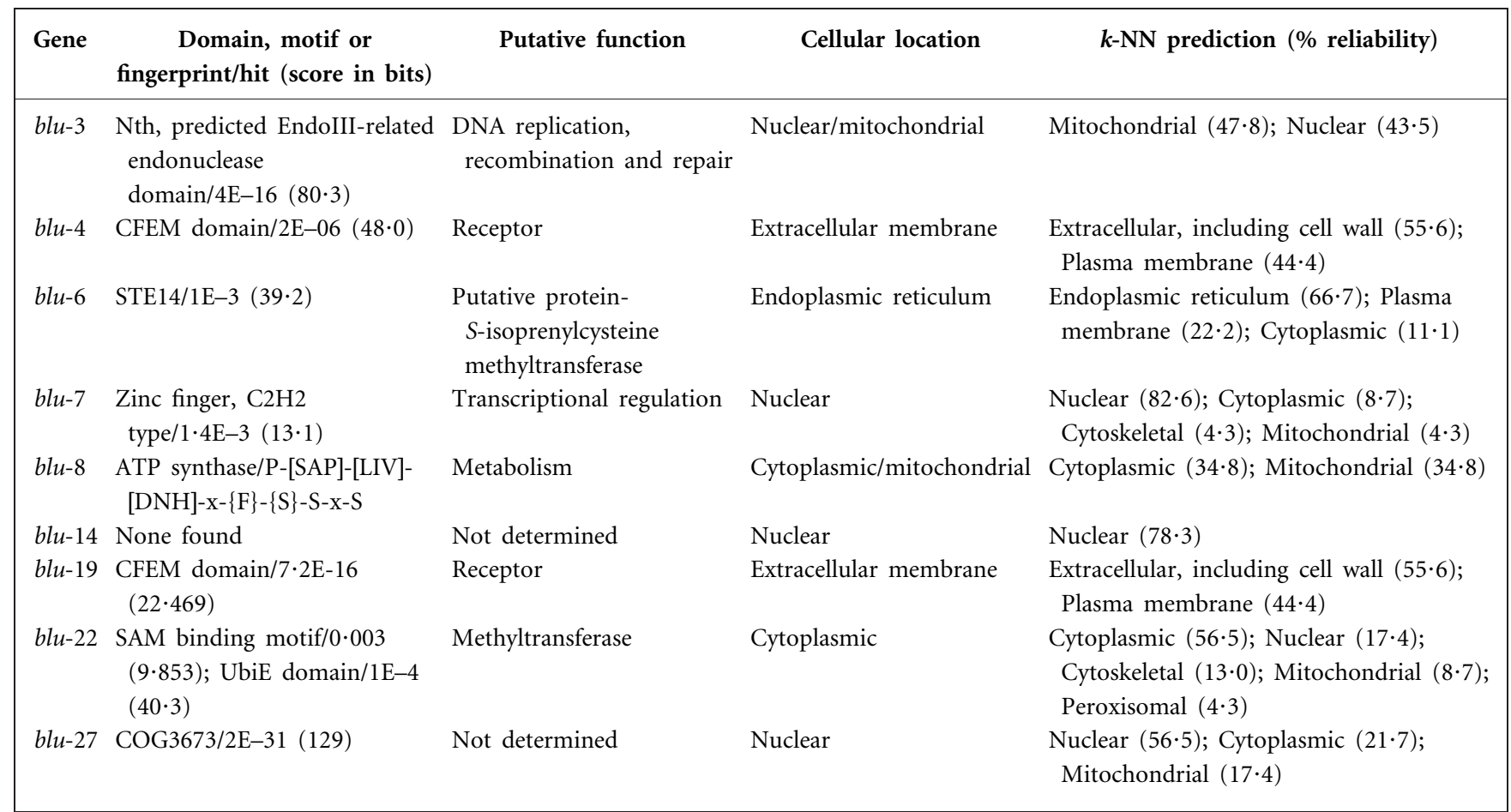


contains a zinc finger domain of the $\mathrm{C} 2 \mathrm{H} 2$ type and BLU-22 has a methylase domain with highest homology to LAEA (Table 4), a regulator of secondary metabolism in Aspergillus spp. (Bok \& Keller, 2004). Even though a mutant in laeA is not defective in sporulation, secondary metabolism has been clearly linked to this process in filamentous fungi. We also identified genes (bld-5 and bld-9) with possible regulatory functions that are repressed by light (Table 3). Additionally, changes in phospholipid content in response to light have been determined in T. viride (Betina, 1984). Inositol regulates the synthesis of phospholipids that in addition to their structural functions serve as secondary messengers in signal transduction (Greenberg \& Lopes, 1996). Furthermore, decrements in inositol in the cell favour the synthesis of phospholipids, which in turn modulate protein kinase $\mathrm{C}$ (PKC) activity and stimulate mitochondrial biogenesis. In N. crassa PKC phosphorylates WC-1, which is then degraded (Franchi et al., 2005).

The early morphogenetic changes observed during the photoconidiation process include the formation of aerial hyphae and ramification of these hyphae (Galun, 1971). It is considered that changes in the cell wall decoration of hyphae due to the accumulation of hydrophobic proteins are an important factor for the formation of aerial hyphae (Wessels et al., 1991). In this regard, our results show that the gene blu-25 encodes a protein with high similarity to the $T$. reesei hydrophobins HfbI and HfbII. The genes blu-4 and blu-19 encode putative plasma membrane proteins with CFEM domains (Table 4); these domains are present in conserved fungal proteins with receptor-like characteristics (Kulkarni et al., 2003). The formation of aerial hyphae starts from vegetative cells, whose primary function is nutrient uptake. This process is likely to require transmembrane receptors that determine polarized growth by rearrangements of the cytoskeleton, as well as modifications of the cell wall, where genes such as blu-20, a putative kinesin, may also play an important role. Fungal cell walls are composed mainly of chitin, $\beta$-(1,3)-linked glucans, other glucans, and proteins (Borkovich et al., 2004). It appears that partial destruction of the cell wall is necessary for growth, so it is likely that in bluelight-mediated morphogenesis chitinase and glucanase activities play important roles. Thus, the observed lightinduced expression of $g l u c 78$ and $b l u-4$ could be explained if the enzymes they encode played a role in conidiophore formation. The emerging aerial hyphae must completely depend on vegetative cells for nutrient uptake. Therefore, metabolic adjustments must be important to support asexual reproduction. Approximately $36 \%$ of the lightinduced genes encode proteins with putative metabolic functions (see Table 1). BLU-29 shows homology to a monosaccharide transporter; the corresponding gene in $A$. nidulans ( $m s t A)$ encodes a high-affinity transporter. MSTA is only produced in the presence of very low concentrations of, or in the absence of, preferred carbon sources such as Dglucose. The N. crassa gene $r c o-3$, which encodes a hexosetransporter-like protein that functions as a glucose sensor, affects both high- and low-affinity glucose transport, glucose regulation of gene expression and carbon repression of conidiation (Madi et al., 1997). Interestingly, we have recently found (Casas-Flores et al., 2006) that the blr genes play a major role in the control of conidiation triggered by a sudden deprivation of glucose. Additionally, the gene $b l u-8$ encodes a protein with an ATP synthase signature and a mitochondrial localization signal, supporting the proposed increase in metabolic activity. These metabolic adjustments may be important to support the differentiation process leading to the production of conidiophores. As already mentioned, exposure of $T$. viride to light results in increments in ATP and cAMP levels, adenylyl cyclase activity and hyperpolarization of the plasma membrane (Kolarova et al., 1992). The activation of the monosaccharide transporter and the ATP synthase might represent a link between carbon and light responses.

Another interesting gene found in our work is $b l u-13$; the protein encoded by this gene is related to fructosyl amino acid oxidases. It is worth mentioning that in A. nidulans the corresponding gene $(f a o A)$ is induced by fructosyl amines and controlled by velvet, which has been identified as a redlight-dependent activator of sexual development and as an inhibitor of asexual development (Jeong et al., 2002). In contrast $b l u-13$ appears to be regulated by blue light and $b l r$ dependent.

Our data indicate that light is an environmental cue that is interpreted as a stress signal that activates cell defence systems as well as a developmental programme leading to perpetuation of the species. Furthermore, we have shown for the first time induction of gene expression in response to red light in fungi and provided evidence for a possible crosstalk between the blue and red light signalling pathways.

\section{ACKNOWLEDGEMENTS}

This work was supported by grant 37601-N from Conacyt to A. H.-E. We are grateful to Dr Octavio Martínez for assistance with bioinformatics analysis, and Beatriz Jiménez and Guillermo Corona for sequencing. T.R.-S., E. U.E.-N. and S.C.-F. are indebted to Conacyt and Concyteg for doctoral fellowships.

\section{REFERENCES}

Adams, T., Wieser, J. \& Yu, J. (1998). Asexual sporulation in Aspergillus nidulans. Microbiol Mol Biol Rev 62, 35-54.

Ballario, P., Vittorioso, P., Magrelli, A., Talora, C., Cabibbo, A. \& Macino, G. (1996). White collar-1, a central regulator of blue light responses in Neurospora, is a zinc finger protein. EMBO J 15, 1650-1657.

Berrocal-Tito, G., Sametz-Baron, L., Eichenberg, K., Horwitz, B. A. \& Herrera-Estrella, A. (1999). Rapid blue light regulation of a Trichoderma harzianum photolyase gene. J Biol Chem 274, 14288-14294.

Berrocal-Tito, G., Rosales-Saavedra, M. T., Herrera-Estrella, A. \& Horwitz, B. A. (2000). Characterization of blue-light and developmental regulation of the photolyase gene phr-1 in Trichoderma harzianum. Photochem Photobiol 71, 662-668. 
Betina, V. (1984). Photoinduced conidiation in Trichoderma viride. Int J Microbiol 2, 55-68.

Blumenstein, A., Vienken, K., Tasler, R., Purschwitz, J., Veith, D., Frankenberg-Dinkel, N. \& Fischer, R. (2005). The Aspergillus nidulans phytochrome FphA represses sexual development in red light. Curr Biol 15, 1833-1838.

Bok, J. W. \& Keller, N. P. (2004). LaeA, a regulator of secondary metabolism in Aspergillus spp. Eukaryot Cell 3, 527-535.

Borkovich, K. A., Alex Lisa, A., Yarden, O. \& 32 other authors (2004). Lessons from the genome sequence of Neurospora crassa: tracing the path from genomic blueprint to multicellular organism. Microbiol Mol Biol Rev 68, 1-108.

Briggs, W. R. \& Christie, J. M. (2002). Phototropins 1 and 2: versatile plant blue-light receptors. Trends Plant Sci 7, 204-210.

Briggs, W. R. \& Huala, E. (1999). Blue-light photoreceptors in higher plants. Annu Rev Cell Dev Biol 15, 33-62.

Carattoli, A., Romano, R., Ballario, P., Morelli, G. \& Macino, G. (1991). The Neurospora crassa carotenoid biosynthetic gene (albino 3) reveals highly conserved regions among prenyltransferases. J Biol Chem 266, 5854-5859.

Casas-Flores, S., Rios-Momberg, M., Bibbins, M., Ponce-Noyola, P. \& Herrera-Estrella, A. (2004). BLR-1 and BLR-2 are key regulatory elements for photoconidiation and mycelial grown in Trichoderma atroviride. Microbiology 150, 3561-3569.

Casas-Flores, S., Rios-Momberg, M., Rosales-Saavedra, T., Martínez-Hernández, P., Olmedo-Monfil, V. \& Herrera-Estrella, A. (2006). Cross talk between a fungal blue-light perception system and the cyclic AMP signaling pathway. Eukaryot Cell 5, 499-506.

Clevel, W. S. \& Devlin, S. J. (1998). Locally-weighted regression: an approach to regression analysis by local fitting. J Am Stat Assoc 83, 596-610.

DeBlasio, S. L., Mullen, J. L., Luesse, D. R. \& Hangarter, R. P. (2003). Phytochrome modulation of blue light-induced chloroplast movements in Arabidopsis. Plant Physiol 133, 1471-1479.

Fankhauser, C. (2001). The phytochromes, a family of red/far-red absorbing photoreceptors. J Biol Chem 276, 11453-11456.

Folta, K. \& Spalding, E. P. (2001). Opposing roles of phytochrome early cryptochrome-mediated growth inhibition. Plant J 28, 333-340.

Franchi, L., Fulci, V. \& Macin, G. (2005). Protein kinase C modulates light responses in Neurospora by regulating the blue light photoreceptor WC-1. Mol Microbiol 56, 334-345.

Froehlich, A. C., Liu, Y., Loros, J. J. \& Dunlap, J. C. (2002). White collar-1, a circadian blue light photoreceptor, binding to the frequency promoter. Science 297, 815-819.

Froehlich, A. C., Noh, B., Vierstra, R. D., Loros, J. \& Dunlap, J. C. (2005). Genetic and molecular analysis of phytochromes from the filamentous fungus Neurospora crassa. Eukaryot Cell 4, 2140-2152.

Galun, E. (1971). Scanning electron microscopy of intact Trichoderma colonies. J Bacteriol 108, 938-940.

Glomset, J. A., Gelb, M. H. \& Farnsworth, C. C. (1990). Prenyl proteins in eukaryotic cells: a new type of membrane anchor. Trends Biochem Sci 15, 139-142.

Greenberg, M. L. \& Lopes, J. M. (1996). Genetic regulation of phospholipids biosynthesis in Saccharomyces cerevisiae. Microbiol Rev 60, 1-20.

Gresik, M., Kolarova, N. \& Farkas, V. (1988). Membrane potential, ATP, and cyclic AMP changes induced by light in Trichoderma viride. Exp Mycol 12, 295-301.

Gresik, M., Kolarova, N. \& Farkas, V. (1989). Light-stimulated phosphorylation of proteins in cell free extracts from Trichoderma viride. FEBS Lett 12, 185-187.
Gressel, J. A. R. W. (1983). Photomorphogenesis. In Encyclopedia of Plant Physiology, new series, vol. 16B, pp. 603-639. Edited by J. A. M. H. Shropshire. Berlin: Springer.

Harding, R. W. \& Turner, R. V. (1981). Photoregulation of the carotenoid biosynthetic pathway in albino and white-collar mutants of Neurospora crassa. Plant Physiol 68, 745-749.

He, Q. \& Liu, Y. (2005). Molecular mechanism of light responses in Neurospora: from light-induced transcription to photoadaptation. Genes Dev 19, 2888-2899.

He, Q., Cheng, P., Yang, Y., Wang, L., Gardner, K. H. \& Liu, Y. (2002). White collar-1, a DNA binding transcription factor and a light sensor. Science 297, 840-843.

Horwitz, B. A., Gressel, J. \& Malkin, S. (1985). Photoperception mutants in Trichoderma: mutants that sporulate in response to stress but not light. Curr Genet 9, 605-613.

Jeong, H.-J., Song, M. H., Back, J. H., Han, D.-M., Wu, X., Monnier, V., Jahng, K.-Y. \& Chae, K.-S. (2002). The veA gene is necessary for the inducible expression by fructosyl amines of the Aspergillus nidulans fao $A$ gene encoding fructosyl amino acid oxidase (amadoriase, EC 1.5.3). Arch Microbiol 178, 344-350.

Kolarova, N., Haplová, J. \& Gresik, M. (1992). Light-activated adenyl cyclase from Trichoderma viride. FEMS Microbiol Lett 72, 275-278.

Kulkarni, R. D., Kelkar, H. S. \& Ralph, R. A. (2003). An eightcysteine-containing CFEM domain unique to a group of fungal membrane proteins. Trends Biochem Sci 28, 118-121.

Langfelder, K., Streibel, M., Jahn, B., Haase, G. \& Brakhage, A. A. (2003). Biosynthesis of fungal melanins and their importance for human pathogenic fungi. Fungal Genet Biol 38, 143-158.

Lewis, Z., Correa, A., Schwerdtfeger, C., Link, K., Xie, X., Gomer, T., Thomas, T., Ebbole, D. \& Bell-Pedersen, D. (2002). Overexpression of white collar-1 (WC-1) activates circadian clock-associated genes, but is not sufficient to induce most light-regulated gene expression in Neurospora crassa. Mol Microbiol 45, 917-931.

Linden, H. (2002). Blue light perception and signal transduction in Neurospora crassa. In Molecular Biology of Fungal Development, pp. 165-185. Edited by H. D. Osiewacz. New York \& Basel: Marcel Dekker.

Linden, H. \& Macino, G. (1997). White collar 2, a partner in bluelight signal transduction, controlling expression of light-regulated genes in Neurospora crassa. EMBO J 16, 98-109.

Linden, H., Ballario, P. \& Macino, G. (1997). Blue light regulation in Neurospora crassa. Fungal Genet Biol 22, 141-150.

Ma, L., Li, J., Qu, L., Hager, J., Chen, Z., Zhao, H. \& Deng, X. W. (2001). Light control of Arabidopsis development entails coordinated regulation of genome expression and cellular pathways. Plant Cell 13, 2589-2607.

Madi, L., McBride, S. A., Bailey, L. A. \& Ebbole, D. J. (1997). $r c o-3$, a gene involved in glucose transport and conidiation in Neurospora crassa. Genetics 146, 499-508.

Rocha-Ramírez, V., Omero, C., Chet, I., Horwitz, B. A. \& HerreraEstrella, A. (2002). Trichoderma atroviride G-protein a-subunit gene tgal is involved in mycoparasitic coiling and conidiation. Eukaryot Cell 1, 594-605.

Sambrook, J., Fritsch, E. F. \& Maniatis, T. (1989). Molecular Cloning: a Laboratory Manual, 2nd edn. Cold Spring Harbor, NY: Cold Spring Harbor Laboratory.

Sancar, A. \& Sancar, G. B. (1988). DNA repair enzymes. Annu Rev Biochem 57, 29-67.

Schmoll, M., Franchi, L. \& Kubicek, C. P. (2005). Envoy, a PAS/LOV domain protein of Hypocrea jecorina (anamorph Trichoderma reesei), 
modulates cellulase gene transcription in response to light. Eukaryot Cell 4, 1998-2007.

Schwerdtfeger, C. \& Linden, H. (2000). Localization and lightdependent phosphorylation of white collar 1 and 2, the two central components of blue light signaling in Neurospora crassa. Eur J Biochem 267, 414-421.

Schwerdtfeger, C. \& Linden, H. (2003). VIVID is a flavoprotein and serves as a fungal blue light photoreceptor for photoadaptation. EMBO J 22, 4846-4855.

Sokolovsky, V. Y., Lauter, F., Muller-Rober, B., Ricci, M., Schmidhauser, T. J. \& Russo, V. E. A. (1992). Nitrogen regulation of blue light-inducible genes in Neurospora crassa. J Gen Microbiol 138, 2045-2049.

Sommer, T., Chambers, J. A. A., Eberle, J., Lauter, F. R. \& Russo, V. E. A. (1989). Fast light-regulated genes of Neurospora crassa. Nucleic Acids Res 17, 5713-5723.

Tomita, H., Soshi, T. \& Inoue, H. (1993). The Neurospora uvs-2 gene encodes a protein, which has homology to yeast RAD18, with unique zinc finger motifs. Mol Gen Genet 238, 225-233.
Ulm, R., Baumann, A., Oravecz, A., Mate, Z., Adam, E., Oakeley, E., Schafer, E. \& Nagy, F. (2004). Genome-wide analysis of gene expression reveals function of the bZIP transcription factor HY5 in the UV-B response of Arabidopsis. Proc Natl Acad Sci U S A 101, 1397-1402.

Vasseur, V., Van Montagu, M. \& Goldman, G. H. (1995). Trichoderma harzianum genes induced during growth on Rhizoctonia solani cell walls. Microbiology 141, 767-774.

Wang, Z., Deak, M. \& Free, S. J. J. (1994). A cis-acting region required for the regulated expression of $\operatorname{grg}-1$, a Neurospora glucoserepressible gene. Two regulatory sites (CRE and NRS) are required to repress grg-1 expression. J Mol Biol 18, 65-74.

Wessels, J. G. H., de Vries, O. M. H., Asgeirsdottir, S. A. \& Achuren, F. H. J. (1991). Hydrophobin genes involved in formation of aerial hyphae and fruit bodies in Schizophyllum. Plant Cell 3, 793-799.

Yang, Y. H., Dudoit, S., Luu, P., Lin, D. M., Peng, V., Ngai, J. \& Speed, T. P. (2002). Normalization for cDNA microarray data: a robust composite method addressing single and multiple slide systematic variation. Nucleic Acids Res 30, e15. 